\title{
Ocorrência de Phakopsora euvitis Ono em Santa Maria, Rio Grande do Sul
}

\author{
Occurrence of Phakopsora euvitis Ono, Santa Maria, Rio Grande do Sul
}

Tânia Maria Bayer ${ }^{1}$ Ivan Francisco Dressler da Costa ${ }^{2}$

\begin{abstract}
Na safra 2004/05, a ferrugem da videira foi RESUMO identificada pela primeira vez em parreirais localizados em Santa Maria/RS. No Brasil, a doença já havia sido identificada em Jandaia do Sul-Paraná (2001), em São Paulo e em Mato Grosso do Sul (2000). A doença é causada pelo fungo Phakopsora euvitis, geralmente disseminado pelo vento $e$ favorecido por condições de umidade elevadas. Em condição ambiente favorável, é possível que o patógeno ataque o hospedeiro intermediário na região ou migre anualmente de áreas atacadas.
\end{abstract}

Palavras-chave: videira, ferrugem da videira, diagnose.

\section{ABSTRACT}

In 2004/05 seanon the grape rust was identified by the first time attacking vineyard located in the Santa Maria/RS region. In Brazil it had already been identified in Jandaia do Sul/PR (2001), São Paulo and Mato Grosso do Sul (2003). The disease is caused by Phakopsora euvitis. The fungi is easily disseminated by wind and favored by high temperature and umidity. Such conditions are normally observed in Santa Maria region what make possible the fungus to survive on alternative host or migrate from other regions.

Key words: grapevine, rust, diagnostic.

A ferrugem da videira é causada pelo fungo Phakopsora euvitis Ono, um parasita obrigatório dependente de um hospedeiro para se desenvolver e reproduzir. O ciclo completo dessa ferrugem ocorre apenas na Ásia, onde existe a planta hospedeira alternativa do fungo, chamada Meliosma myriantha, que não ocorre no Brasil (FERRARI \& NOGUEIRA, 2005).

As ferrugens são doenças conhecidas pela capacidade de dispersão por longas distâncias através do vento. A ferrugem da videira, inicialmente constatada no Paraná, foi também observada em parreirais no Estado de São Paulo e, atualmente, há suspeitas da sua ocorrência em Minas Gerais (NORDESTE RURAL, 2005).

No Brasil, apenas as fases uredinial e telial do fungo $\boldsymbol{P}$. euvitis foram observadas no campo, com a formação de esporos denominados uredósporos e teliósporos, respectivamente. Os uredósporos constituem o inóculo primário e secundário da doença e são disseminados pelo vento, podendo atingir grandes distâncias. A sobrevivência do patógeno, de uma safra para outra, é altamente favorecida pela presença de tecidos verdes na planta durante todo o ano, por invernos amenos e pelo cultivo continuado da videira em regiões que produzem mais de uma safra anual (FERRARI \& NOGUEIRA, 2005). A doença ocorre preferencialmente em folhas maduras, causando a desfolha precoce das plantas infectadas (TESSMANN et al., 2004). Os sintomas caracterizam-se pela formação de pústulas de coloração amarela na face inferior das folhas e, na face superior correspondente às pústulas,

${ }^{1}$ Curso de Agronomia, Universidade Federal de Santa Maria (UFSM), Santa Maria, RS, Brasil.

${ }^{2}$ Departamento de Defesa Fitossanitária,UFSM. Clínica Fitossanitária, Campus Universitário, 97105-900. Santa Maria, RS. Brasil. Email: idresler@smail.ufsm.br. Autor para correspondência. 
aparecem áreas necrosadas. Essas folhas tornam-se amarelas e secam, podendo ocorrer desfolha precoce se o ataque for intenso, e redução do crescimento do porta-enxerto e da produção de frutos. As pústulas da ferrugem são formadas cinco a seis dias após a inoculação, em temperaturas de 16 a $30^{\circ} \mathrm{C}$. As temperaturas mínima, ótima e máxima para a germinação dos uredósporos são 8,24 e $32^{\circ} \mathrm{C}$, respectivamente (FERRARI \& NOGUEIRA, 2005). No Paraná, a doença ocorreu no período de janeiro a junho, em 2001; de janeiro a abril, em 2002 e de dezembro a junho, em 2003. (FERRARI \& NOGUEIRA, 2005).

Variedades americanas como Niágara e Isabel e diversos porta-enxertos são mais suscetíveis ao patógeno do que as variedades de uva européia. Em relação ao controle químico, até o momento não há fungicidas registrados para o controle da doença, embora algumas pesquisas estejam sendo realizadas, com resultados satisfatórios (FERRARI \& NOGUEIRA, 2005).

O patógeno foi detectado na localidade de Três Barras, região pertencente à Santa Maria, sobre videiras da variedade Isabel. Amostras de videira (Vitis labrusca L.), constituídas de folhas, ramos e frutos verdes, encaminhadas à Clínica Fitossanitária, localizada na Universidade Federal de Santa Maria, apresentaram manchas amareladas na face abaxial das folhas, de forma e tamanhos variáveis. Essas amostras foram submetidas à análise visual microscópica e estereoscópica, e, de acordo com suas características morfológicas, evidenciou tratar-se de Phakopsora euvitis.

O exame do material infectado para visualização de uredósporos, nas lâminas submetidas ao microscópio de luz, revelou que o fungo presente nas manchas, com aspecto de pó amarelo, corresponde a Phakopsora euvitis Ono (ONO, 2000), agente causal da ferrugem da folha da videira. O P. euvitis, identificado em videira, no município de Santa Maria, é o agente etiológico da ferrugem.

Visto que o fungo desenvolve-se bem em climas distintos, há grande probabilidade de que esta doença se dissemine rapidamente por todas as regiões produtoras do Estado do Rio Grande do Sul, causando danos severos à cultura. A ferrugem é considerada pelo Ministério da Agricultura, Pecuária e Abastecimento (MAPA) como sendo praga A2, isto é, presente no país, mas restrita a algumas áreas, com risco potencial da causar danos econômicos.

Devido às condições ambientes do Estado do Rio Grande do Sul, o fungo, que necessita de um hospedeiro vivo para permanecer viável, possivelmente não tenha apenas a videira como seu hospedeiro, já que esta planta não oferece tecidos verdes durante parte do outono e do inverno. Assim, é de se supor que o fungo possa encontrar hospedeiros alternativos no referido Estado para completar o seu ciclo de vida, e, conseqüentemente, os produtores deverão adotar medidas para o controle desta nova doença, não sendo suficiente apenas a pulverização das plantas com fungicidas, e sim a utilização de manejo integrado da doença. O aumento nos custos de produção poderá ser significativo, em razão dos gastos com produtos fitossanitários necessários para o combate ao fungo. Além de exigir maiores investimentos, a ferrugem da videira requer melhores tecnologias na aplicação e produtos fitossanitários, aplicação que deverá ser realizada de maneira racional para amenizar os impactos ambientais.

\section{REFERÊNCIAS}

FERRARI, J.T.; NOGUEIRA, E.M.C. Ferrugem da videira. Capturado em 12 jun 2005. Online. Disponivel na Internet: h t t p : / / w w w. bi ologico.sp.gov.br/ferrugem / ferrugem_videira.htm

NORDESTE RURAL. Uma ameaça aos parreirais brasileiros. Capturado em 20 jul 2005. Online. Disponivel na Internet: http://www.nordesterural.com.br/dev/nordesterural/ matler.asp?newsId=536

ONO, Y. Taxonomy of the Phakopsora ampelopsidis species complex on vitaceous hosts in Asia including a new species, $\boldsymbol{P}$. euvitis. Mycologia, v.92, p.154-173, 2000.

TESSMANN, D.J. et al. Grape rust caused by Phakopsora euvitis, a new disease for Brazil. Fitopatologia Brasileira, v.29, n3, p.338, 2004. 